Article

\title{
Optimization of Copper Thermocompression Diffusion Bonding under Vacuum: Microstructural and Mechanical Characteristics
}

\author{
Michail Samouhos ${ }^{1, *}$, Antonis Peppas ${ }^{1}{ }^{\oplus}$, Panagiotis Angelopoulos ${ }^{1}$, Maria Taxiarchou ${ }^{1}$ and \\ Petros Tsakiridis 2 (D) \\ 1 Laboratory of Pyrometallurgy, School of Mining and Metallurgical Engineering, National Technical \\ University of Athens, 9 Heroon Polytechniou St, 15780 Athens, Greece; peppas@metal.ntua.gr (A.P.); \\ pangelopoulos@metal.ntua.gr (P.A.); taxiarh@metal.ntua.gr (M.T.) \\ 2 Laboratory of Physical Metallurgy, School of Mining and Metallurgical Engineering, National Technical \\ University of Athens, 9 Heroon Polytechniou St, 15780 Athens, Greece; ptsakiri@central.ntua.gr \\ * Correspondence: msamouhos@metal.ntua.gr; Tel.: +30-2107724482
}

Received: 11 August 2019; Accepted: 24 September 2019; Published: 26 September 2019

\begin{abstract}
The optimization of the autogenous diffusion copper bonding via thermocompression at vacuum environment was investigated. The influence of various bonding parameters on the interdiffusion efficiency was studied in detail at the micro (SEM-EBSD) and nano (TEM) scales. Bonding at $1000{ }^{\circ} \mathrm{C}$ for $90 \mathrm{~min}$ under pressure $(10 \mathrm{MPa})$ presented optimum structural and mechanical results. Under these conditions, interdiffusion phenomena were observed at a significant extent through the swelling transformation of existing fine grains or the formation of equiaxed copper grains with an orientation parallel to the bond interface. Transmission electron microscopy revealed the importance of the grain size of the base material on the bond quality. In the regions with fine-sized copper grains, the formation of small equiaxed recrystallized twins was observed. Their length within the bonding zone was in the order of 200 and $400 \mathrm{~nm}$. On the contrary, in the regions with coarse grains the interdiffusion was poorer. The processing temperature and duration presented a significant effect on the bonding strength (BS). BS exceeded $100 \mathrm{MPa}$ in case of processing conditions of $T \geq 850^{\circ} \mathrm{C}$ and $t \geq 60 \mathrm{~min}$, while the maximum BS value achieved ( $\approx 180 \mathrm{MPa}$ ) was comparable with the respective value of the base material. The microhardness of the optimum bond reached $55 \mathrm{HV}$ - slightly higher in comparison to the hardness of the initial copper material. The results indicated that the proposed thermocompression process is appropriate for the production of $\mathrm{Cu}-\mathrm{Cu}$ bonded structures that can be potentially used as electrical components under mechanical stress.
\end{abstract}

Keywords: copper; thermocompression; bonding; diffusion; microstructure characterization

\section{Introduction}

Non-fusion bonding consists of a solid-state process in which the joining between two metal surfaces is achieved via interdiffusion and grain growth across the bonding interface [1,2]. In the case of $\mathrm{Cu}-\mathrm{Cu}$ autogenous bonding, several non-fusion techniques have been developed, including low and high-temperature thermocompression, forge and roll, friction, explosion, electric resistance, and ultrasonic processing [1,3-6]. Vacuum thermocompression consists of the most widely followed process due to its sufficiently controlled conditions and the formation of $\mathrm{Cu}-\mathrm{Cu}$ bonds with various physicochemical specifications according to respective applications.

Low temperature thermocompression (performed between 150 and $450{ }^{\circ} \mathrm{C}$ ) (LTT) and room temperature compression $\mathrm{Cu}-\mathrm{Cu}$ bonding have been extensively studied due to their potential application in future three-dimensional integrated circuits. LTT processes impart high electric 
conductivity and low-medium mechanical strength properties, while they assure low thermal stress avoiding damages to the bonded microelectronics [7]. Bonding (tensile) strength (BS) values of up to $70 \mathrm{MPa}$ have been reported in the case of thermocompression between 200 and $400{ }^{\circ} \mathrm{C}$ [8-10], while a BS value around $10 \mathrm{MPa}$ is achieved at room temperature compression [11]. Exceptionally high BS values ( $>200 \mathrm{MPa}$ ) have been referred to in the case of annealed and pre-treated copper surfaces using $\mathrm{H}_{2} /$ Ar plasma or formic acid vapor [12].

On the other hand, high-temperature $\mathrm{Cu}-\mathrm{Cu}$ bonding has not been thoroughly investigated. A limited number of studies describe that the process is performed using a diffusion bonding furnace with hydraulic load equipment in the temperature range of $600-1000^{\circ} \mathrm{C}[13,14]$. Moreover, recently there has been an interest in $\mathrm{Cu}-\mathrm{Cu}$ bonded structures with advanced mechanical properties that can be used for the construction of bar-wound stators in vehicles [15] or as components in particle accelerators [16,17]. High-temperature bonding technology is compatible with these applications as the existence of thermal deformation phenomena does not consist of a deterrent factor.

The current investigation aims for the optimization of a simple, high-temperature $\left(750-1000{ }^{\circ} \mathrm{C}\right)$ $\mathrm{Cu}-\mathrm{Cu}$ bonding process using an induction vacuum furnace. The bond quality, in terms of bonding conditions, was studied via microscopy and mechanical tests, while the optimum accomplished bond was examined using scanning electron microscopy (SEM) in conjunction with electron backscatter diffraction (EBSD) and transmission electron microscopy (TEM).

\section{Materials and Methods}

\section{1. $\mathrm{Cu}$-Cu Thermocompression Bonding}

Commercially pure (99.9\% purity) Cu foils ( $200 \mu \mathrm{m}$ thickness, $2 \mathrm{~cm}$ width) were used for the bonding tests. The foils were initially placed for $10 \mathrm{~s}$ in a hydrochloric acid bath (5\% v/v) and subsequently were cleaned with acetone aiming to the removal of a potential thin oxide film, which could impede the interdiffusion mechanism during the bonding process. A stainless steel clamp with an appropriately designed recess was used for the tightening of 28 foils (Figures 1 and 2a). During its screwing, the clamp with the sample was compressed at $10 \mathrm{Mpa}$. Literature data and preliminary tests showed that the compression between 7 and $10 \mathrm{MPa}$ is efficient for $\mathrm{Cu}-\mathrm{Cu}$ bonding performance. The superficial interdiffusion between the foils and the clamp was avoided by the coating of the clamp's recess with a thin, fine powdered graphite layer. Bonding tests were performed using a customized Termolab induction graphite vacuum furnace in the temperature range between 750 and $1000{ }^{\circ} \mathrm{C}$ under $5 \times 10^{-2}$ mbar pressure. The furnace's chamber consists of a vertical cylindrical graphite tube (internal dimensions: $d=24 \mathrm{~cm}, h=21 \mathrm{~cm}$ ) capped by bottom and top graphite elements ensuring heating uniformity (Figure 2b).

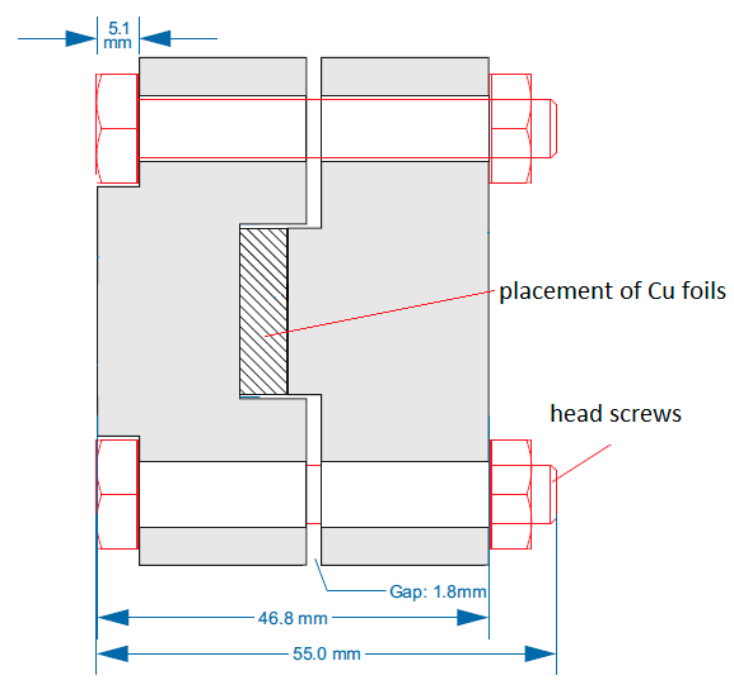

Figure 1. Technical drawing of the clamp used for the autogenous copper bonding. 


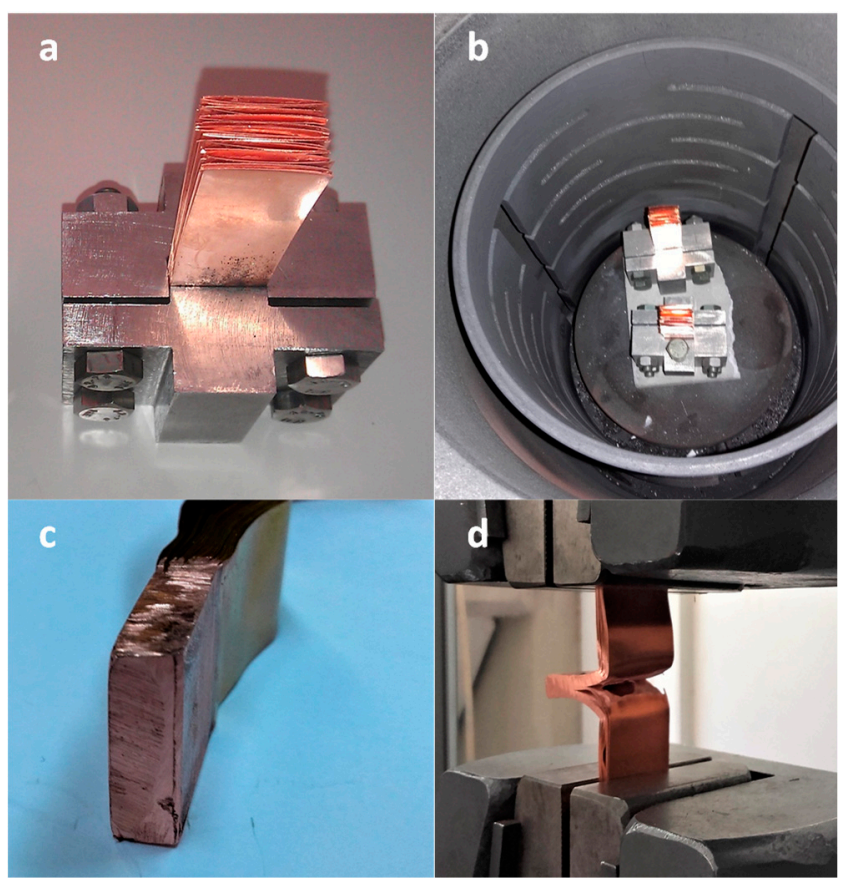

Figure 2. Processing steps of autogenous $\mathrm{Cu}$ bonding and mechanical characterization; (a) $\mathrm{Cu}$ foils in the pressing clamp, (b) placement of samples in the graphite furnace, (c) Cu foils after bonding and (d) bonding strength test.

\subsection{Diffusion Bonding Characterization}

The microstructure of the copper bonds was initially examined by optical metallurgical microscopy (BX41M model, Olympus, Shinjuku, Japan), while a more detailed investigation was performed using a JEOL 6380 LV Scanning Electron Microscope (JEOL, Tokyo, Japan) at 20 kV, coupled with Energy Dispersive System (SEM-EDS). Electron backscatter diffraction (EBSD) analysis was carried out, focusing on the grains generation and crystals orientation in the diffusion zone, using a Nordlys EBSD detector (Oxford Instruments, Abingdon, England). The sample under investigation was tilted $70^{\circ}$ to the electron beam and placed at $15 \mathrm{~mm}$ of working distance, whereas the EBSD orientation maps were recorded from a selected region of the diffusion zone at $20 \mathrm{kV}$, with a scan step size of $300 \mathrm{~nm}$. Prior to the SEM examination and the EBSD characterization, all samples were prepared by grinding and mechanical polishing. SEM samples were polished with a $6 \mu \mathrm{m}$ and $1 \mu \mathrm{m}$ diamond paste, and then successfully etched with a $\mathrm{NH}_{4} \mathrm{OH}$ and $\mathrm{H}_{2} \mathrm{O}_{2}$ solution. The EBSD sample (optimum bond) was subjected to a final polishing stage using a $0.1 \mu \mathrm{m}$ diameter colloidal silica suspension. Nanoscale investigation of the optimum bonded specimen was performed with a high resolution JEOL JEM-2100 LaB6 transmission electron microscope (HRTEM) (JEOL, Tokyo, Japan), operating at $200 \mathrm{kV}$. Ion-beam milling at $5 \mathrm{kV}$ in a Gatan Precision Ion Polishing system (PIPS, Gatan Inc., Pleasanton, CA, USA) was used for the sample's thinning. Bonding strength measurements were carried out at room temperature and the stress-strain curves were obtained using a universal testing machine (Model 4482, max load: $100 \mathrm{kN}$ ) at a crosshead speed of $1 \mathrm{~mm} / \mathrm{min}$ (Figure 2c,d). Vickers microhardness tests were conducted with a Shimadzu type M microhardness tester (Shimadzu, Kyoto, Japan), working at a magnification of $500 \times$.

\section{Results and Discussion}

The bonding consists of a multi-factorial process mainly affected by the applied pressure on the sample, the heating temperature/duration, and the vacuum quality. According to the literature, these parameters dramatically affect the plastic deformation of the surface asperities, resulting in the increase of contact between the surfaces and control of the diffusion mechanism of the atoms across 
the interface. The quality of thermocompressed $\mathrm{Cu}-\mathrm{Cu}$ bonds, in respect to temperature and time processing, is examined in the current study. The parametric tests were performed under a standard loading pressure $(10 \mathrm{MPa})$ and vacuum degree value $\left(5 \times 10^{-2} \mathrm{mbar}\right)$.

\subsection{Microstructural Investigation}

In order to investigate the effect of temperature and duration on bonding, several samples were subjected to morphological examination by means of optical, scanning, and transmission electron microscopy. The section micrographs of Figure $3(\mathrm{a} 1, \mathrm{~b} 1)$ presents, at horizontal direction, the bond line formations between 5 foils bonded at $935^{\circ} \mathrm{C}$ for 45 and $90 \mathrm{~min}$, respectively. As can be seen, the join quality is improved in the case of a more prolonged processing time. Figure $3(\mathrm{a} 2, \mathrm{~b} 2)$ shows, at higher magnification, the bond line number 1 at the same conditions. Undesirable intermediate voids are clearly visible in the case of the sample submitted to bonding for $45 \mathrm{~min}$ (Figure 3(a2)). On the contrary, voids are decreased, a recrystallization process is taking place, and elongated grains are grown in the interface of the sample processed for $90 \mathrm{~min}$ (Figure 3(b2)).
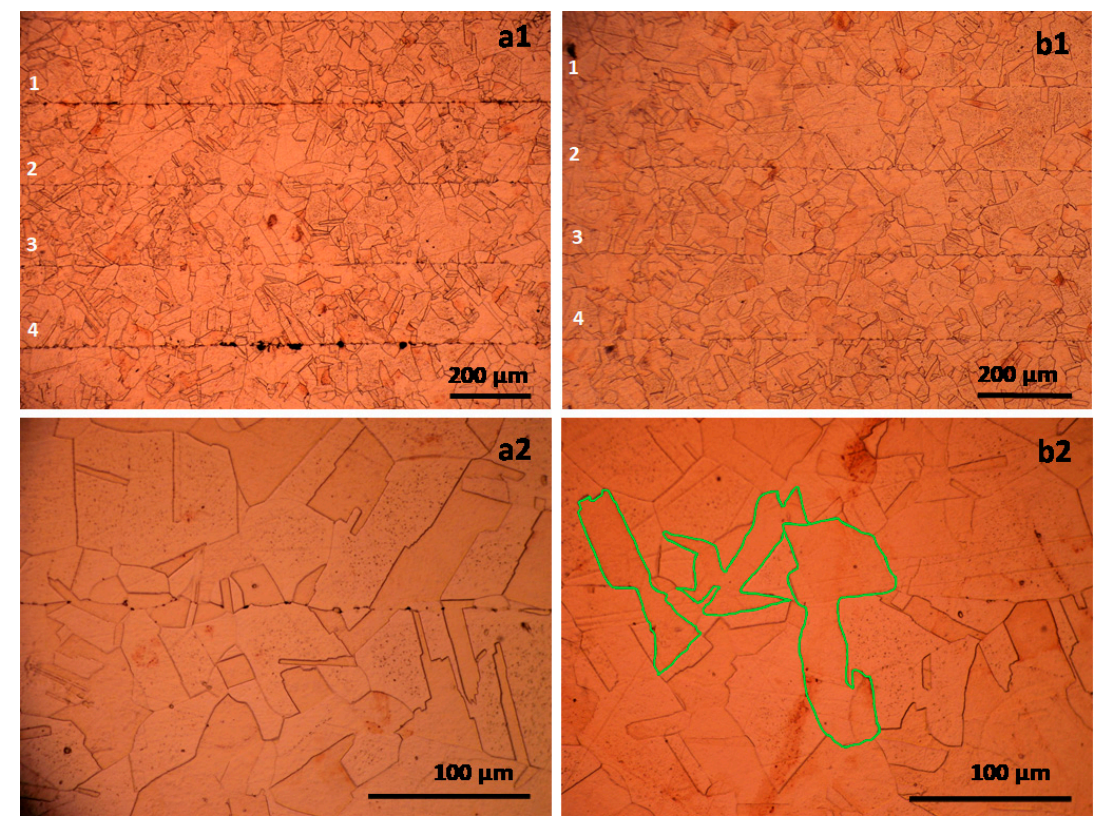

Figure 3. Metallographic micrographs of $\mathrm{Cu}-\mathrm{Cu}$ bond cross sections presenting the interfaces between the copper layers. Bonding conditions: sample (a) $935{ }^{\circ} \mathrm{C} / 45 \mathrm{~min}$, sample (b) $935^{\circ} \mathrm{C} / 90 \mathrm{~min}$ (the numbering corresponds to the bonding lines).

The quality of bonding zones in terms of processing temperature is vividly revealed by scanning electron microscopy. After the sample's processing at $750{ }^{\circ} \mathrm{C}$, the existence of a well-visible continuous interface between the copper layers indicates the formation of a low strength bond (Figure 4(a1,a2)). By increasing processing temperature to $935^{\circ} \mathrm{C}$, the interdiffusion process among the grains becomes more intense, and the unbonded zone is limited in specific regions (Figure 4(b1,b2)). Further temperature increments at $1000{ }^{\circ} \mathrm{C}$ lead to the creation of a uniform diffusion zone along the bond interface with minor visible unbonded regions. At this temperature, the interfacial discontinuity has been eliminated and a recrystallization has been achieved. Scanning electron microscopy indicates the absence of annealing-related recrystallization phenomena by temperature rising from 750 to $1000^{\circ} \mathrm{C}$.

In order to understand the grains evolution and their final orientation in the bonding zone, the examination of the cross-sectional thermocompressed specimens, produced under optimum bonding conditions (i.e., heating for $90 \mathrm{~min}$ at $1000{ }^{\circ} \mathrm{C}$ ), was carried out by electron backscatter diffraction (EBSD) analysis (Figure 5). 

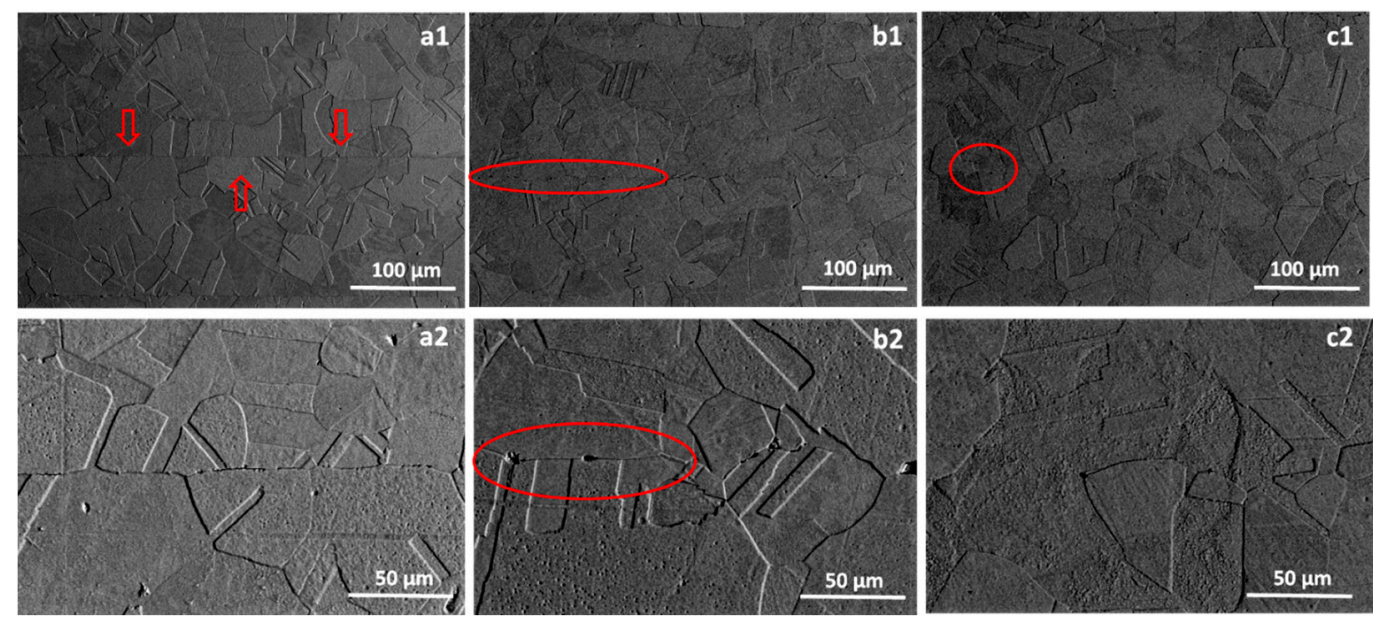

Figure 4. SEM micrographs of $\mathrm{Cu}-\mathrm{Cu}$ bond cross sections presenting the interfaces between the copper layers. Bonding conditions: sample (a) $750{ }^{\circ} \mathrm{C} / 90 \mathrm{~min}$, sample (b) $935^{\circ} \mathrm{C} / 90 \mathrm{~min}$ and sample (c) $1000{ }^{\circ} \mathrm{C} / 90 \mathrm{~min}$.
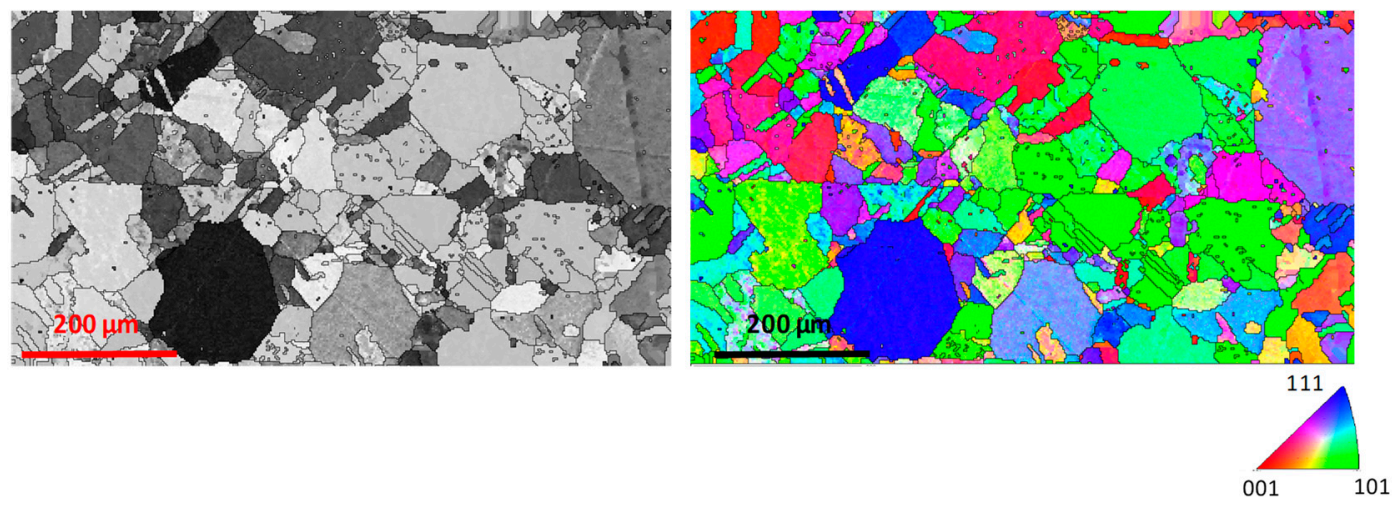

Figure 5. EBSD Band Contrast (left) and Inverse Pole Figure (IPF) (right) maps in the bonding zone. Bonding conditions of specimen: $1000{ }^{\circ} \mathrm{C} / 90 \mathrm{~min}$.

It is evident that the grains size distribution of copper base alloy has not been affected by the thermocompression process. The observed interface is strongly related to the size of the primary copper grains. The smaller $\mathrm{Cu}$ primary grains support either the evolution of new finer equiaxed grains $(2-5 \mu \mathrm{m})$ of similar orientation with the initial matrix, or subserve the swelling transformation of the existing ones and their interdiffusion between the neighbor plate matrix (3-10 $\mu \mathrm{m})$; consequently, the cohesion of the bonded plates is improved. Under the optimum thermocompression bonding conditions, frequent atomic and interface migration between contiguous copper grains has been observed, mainly due to the temperature increase under pressure, leading to the improvement of grain boundaries and the microstructure refining. On the other hand, in the case of large $\mathrm{Cu}$ grains, the diffusion zone in the interface is relatively limited $(\approx 1 \mu \mathrm{m})$ and the consistency seems to be restrained. To clarify further, the copper bonding zone morphology and to investigate the interfacial microstructure formed by the diffusion bonding process, the interface of the optimum bonded specimen was additionally studied via TEM in cross-section. Interface regions with coarse (100-200 $\mu \mathrm{m})$ and fine $(<50 \mu \mathrm{m})$ grains were isolated for observation (Figure 6).

In the case of coarser copper grains, the thermocompression process does not significantly affect the copper diffusion mechanism, as the detected interface zone is very limited and presents a size in the range of $200 \mathrm{~nm}$ and $500 \mathrm{~nm}$. A closer inspection revealed the existence of short vacancies, exhibiting a width of about 5-10 $\mathrm{nm}$. On the contrary, in the case of the smaller neighbor copper grains, the bonding interface seems to be much higher $(3-5 \mu \mathrm{m})$. The microstructure was composed of small equiaxed grains, with recrystallization twins in places. Some of the developed grains length within 
the bonding zone was in the order of 200 and $400 \mathrm{~nm}$, while dislocations were observed randomly dispersed in the copper matrix.
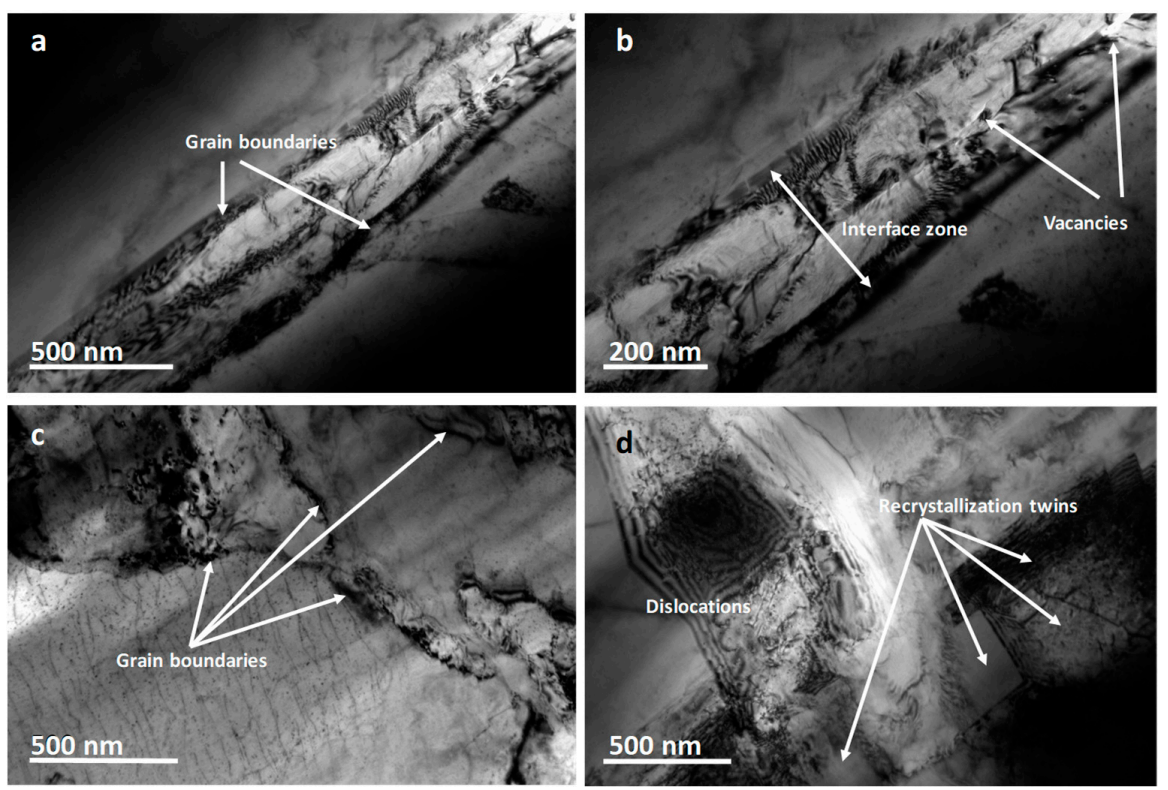

Figure 6. Transmission electron microcopy images in bonding zone applied in grains with different size: (a,b) grain size 100-200 $\mu \mathrm{m},(\mathbf{c}, \mathbf{d})$ grain size $\leq 50 \mu \mathrm{m}$.

\subsection{Mechanical Properties}

Bonding strength consists of a critical parameter for the utilization of autogenous $\mathrm{Cu}$ bonded components in industrial applications. BS values of specimens processed under different bonding temperature and time conditions were measured. The increase of the processing temperature from 750 to $1000{ }^{\circ} \mathrm{C}$ leads to the increase of BS value from 50 to $180 \mathrm{MPa}$ (Figure 7). The notable Cu-Cu diffusion improvement by the temperature rising between 935 and $1000{ }^{\circ} \mathrm{C}$ can be attributed to the increase of the kinetic energy of copper atoms as the temperature is relatively close to their melting point. Computational investigation at an atomic level is necessary in order for the copper interdiffusion to progress in relation to temperature increase to be interpreted on a theoretical basis. Relative studies have shown that displacement of the copper atoms on a substrate can take place even at gentle experimental conditions [18]. Correspondingly, an increase of the processing duration from 20 to $90 \mathrm{~min}$ at $935^{\circ} \mathrm{C}$ raises the BS value from 27 to $120 \mathrm{MPa}$ (Figure 8). The results are in accordance with the microstructural examination as it was previously described, indicating a strong correlation between the temperature/duration of the bonding and the interdiffusion efficiency. The highest BS value was achieved in the case of processing at $1000{ }^{\circ} \mathrm{C}$ for $90 \mathrm{~min}$. Under these conditions, the tensile failure occurred at $180 \mathrm{MPa}$, a value which is comparable with the respective value of the base material (BM) [19]. The morphology of the bonding strength curves indicates a good ductile behavior in case of processing temperatures up to $1000^{\circ} \mathrm{C}$ for $\leq 60 \mathrm{~min}$. More aggressive diffusion bonding conditions resulted in the increasing of a final BS value.

Figure 9 presents the fractographs of $\mathrm{Cu}-\mathrm{Cu}$ bonds fabricated at 750 and $1000{ }^{\circ} \mathrm{C}$. According to Figure $9 a, b$, it can be observed that the solid-state diffusion reaction successfully proceeded in the case of bonding at $1000{ }^{\circ} \mathrm{C}$. The grains of the $\mathrm{Cu}$ plates have been interspersed themselves and a "cup and cone" pattern caused by microvoid coalescence, which is characteristic of a ductile fracture mechanism. That is why the bond under investigation exhibited similar strength value with the corresponding of the base metal. In all cases the area presented extensive plastic deformation with large dimples, accompanied by void formation between the $\mathrm{Cu}$ plates. It should be noted that in a soft matrix (here pure $\mathrm{Cu}$ ), the void nucleation predominately occurs by grains decohesion. Furthermore, due to heating of the whole parts, no distinct heat-affected zone has been detected. On the other hand, 
in the case of bonding at $750^{\circ} \mathrm{C}$ (Figure 9c,d), rounded, dendritic structures were observed, which are indicative of an incipient diffusion mainly due to deficient heat treatment.

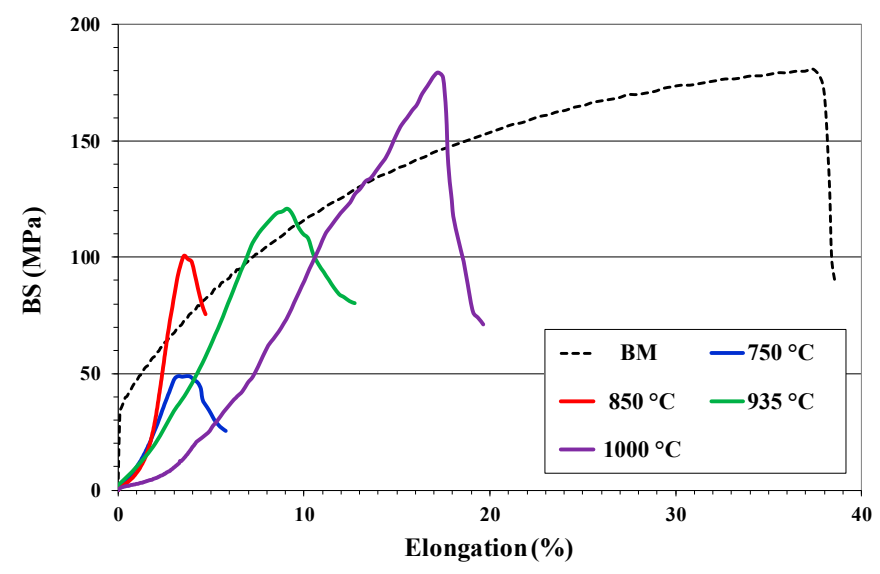

Figure 7. Bonding strength of the $\mathrm{Cu}-\mathrm{Cu}$ bond in relation to the bonding temperature (processing for 90 min); BM: base material.

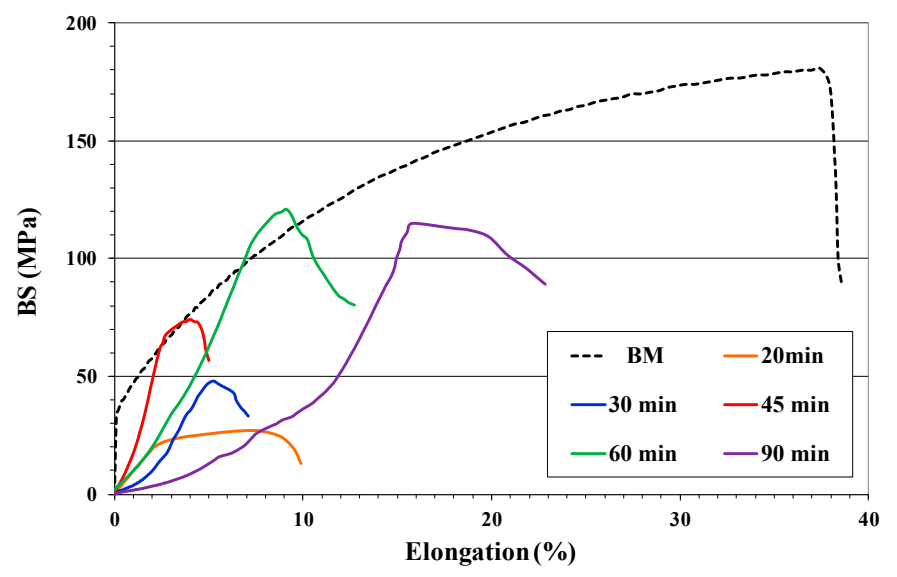

Figure 8. Bonding strength of the $\mathrm{Cu}-\mathrm{Cu}$ bond in relation to the bonding duration (processing at $\left.935^{\circ} \mathrm{C}\right)$.
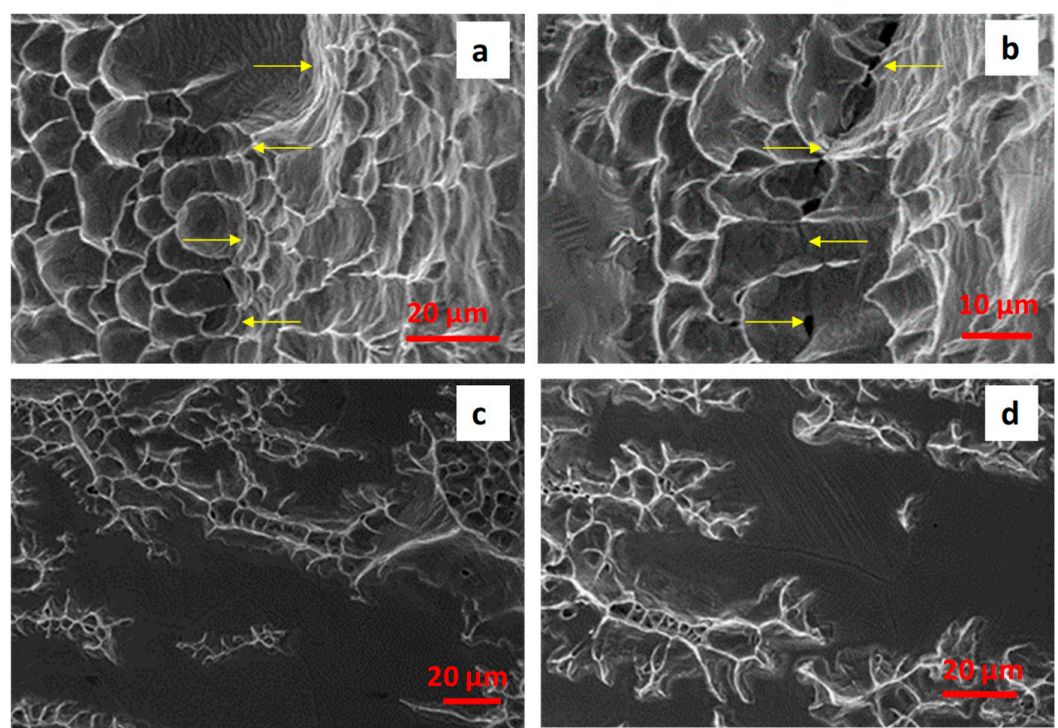

Figure 9. SEM fractographs of copper bonds; $(\mathbf{a}, \mathbf{b})$ : Interface of bond fabricated at $1000{ }^{\circ} \mathrm{C} / 90 \mathrm{~min}$ (the arrows show the interface orientation between the partially detached $\mathrm{Cu}$ plates), $(\mathbf{c}, \mathbf{d})$ : fractured surfaces of $\mathrm{Cu}$ plates bonded at $750^{\circ} \mathrm{C} / 90 \mathrm{~min}$. 
The microhardness distribution across the bonding region of the samples processed for $90 \mathrm{~min}$ at 935 and $1000{ }^{\circ} \mathrm{C}$ (samples b and c, respectively, according to Figure 4) is presented in Figure 10. The measurements, in the case of the optimum sample $\left(90 \mathrm{~min}\right.$ at $1000{ }^{\circ} \mathrm{C}$ ), reveal an increase of the hardness in the bonding interlayer, whereas the corresponding values for the base material (BM) are lower. The hardening of the interlayer can be attributed to the microstructure refinement, after the thermocompression process, and to the development of significant amount of equiaxed finer size grains, due to copper diffusion between the primary metallic plates. The results are in accordance with the EBSD micrograph, in which the presence of fine equiaxed grains distribution in the primary metallic copper plates was observed.
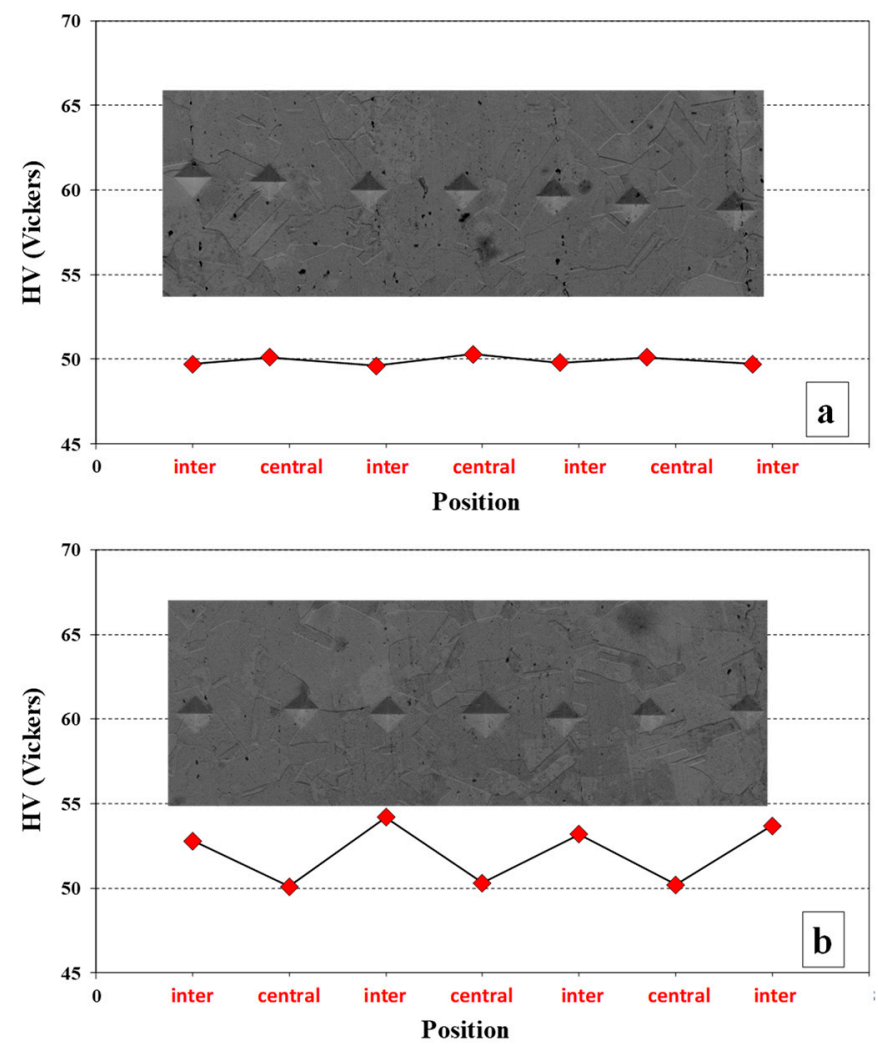

Figure 10. Transvesre Hardness distribution across the bonding region; (a) processing for $90 \mathrm{~min}$ at $935^{\circ} \mathrm{C}$, (b) processing for $90 \mathrm{~min}$ at $1000{ }^{\circ} \mathrm{C}$ (inter: interlayer between the foils, central: the central point of the foil along its thickness).

\section{Conclusions}

The aim of the current study was the optimization of the autogenous high-temperature copper diffusion bonding process. The micro and nano structure of the bonds, as well as their mechanical properties were investigated. The main outcomes derived by the experimental procedure are as follows:

1. $\mathrm{Cu}-\mathrm{Cu}$ bonds with advanced mechanical properties were successfully formatted through a thermocompression process under vacuum. Commercial copper foils with $200 \mu \mathrm{m}$ thickness were used for the bonding tests, while a pressure of $10 \mathrm{MPa}$ was applied.

2. The increase of the bonding temperature, from 750 to $1000{ }^{\circ} \mathrm{C}$, and the duration, from 20 to $90 \mathrm{~min}$, significantly improved the bonding strength of the copper bonds. The highest ultimate BS $(180 \mathrm{MPa})$ approached the respective value of the base material, and was achieved at $1000{ }^{\circ} \mathrm{C}$ for $90 \mathrm{~min}$. The transverse microhardness of the bond reached $55 \mathrm{HV}$, slightly higher in comparison to the respective value of the base material.

3. Electron backscatter diffraction (EBSD) investigation, of the optimum bonded specimen, reveals a satisfactory interdiffusion growth in regions with finer grains. Transmission electron microscopy 
revealed the formation of small equiaxed recrystallized twin crystals in the bonding zone with a size ranging from 200 to $400 \mathrm{~nm}$.

4. The above mechanical and microstructural data indicated that the developed copper-bonded structure could be successfully used in devices that are submitted to intense mechanical stress (i.e., bar-wound stators in vehicles).

Author Contributions: M.S., A.P., P.A. and P.T. designed and performed the experiments. M.S. additionally wrote the manuscript. M.T. contributed to the discussion of the experimental data.

Funding: This research received no external funding.

Conflicts of Interest: The authors declare no conflict of interest.

\section{References}

1. Messler, R.W. Joining of Materials and Structures. From Pragmatic Process to Enabling Technology, 1st ed.; Elsevier: Burlington, MA, USA, 2004.

2. Peng, L.; Lim, D.F.; Zhang, L.; Li, H.Y.; Tan, C.S. Effect of prebonding anneal on the microstructure evolution and $\mathrm{Cu}-\mathrm{Cu}$ diffusion bonding quality for three-dimensional integration. J. Electron. Mater. 2012, 41, 2567-2572. [CrossRef]

3. Tian, Y.; Wang, C.; Lum, I.; Mayer, M.; Jung, J.P.; Zhou, Y. Investigation of ultrasonic copper wire wedge bonding on $\mathrm{Au} / \mathrm{Ni}$ plated Cu substrates at ambient temperature. J. Mater. Process. Technol. 2008, 208, 179-186. [CrossRef]

4. Sahin, M. Joining of aluminium and copper materials with friction welding. Int. J. Adv. Manuf. Technol. 2010, 49, 527-534. [CrossRef]

5. Ebberta, C.; Schmidt, H.C.; Rodmanc, D.; Nürnbergerc, F.; Hombergb, W.; Maierc, H.J.; Grundmeier, G. Joining with electrochemical support (ECUF): Cold pressure welding of copper. J. Mater. Process. Technol. 2014, 214, 2179-2187. [CrossRef]

6. Chen, S.Y.; Wu, Z.W.; Liu, K.X.; Li, X.J.; Luo, N.; Lu, G.X. Atomic diffusion behavior in Cu-Al explosive welding process. J. Appl. Phys. 2013, 113, 044901. [CrossRef]

7. Panigrahy, A.K.; Chen, K.N. Low temperature $\mathrm{Cu}-\mathrm{Cu}$ bonding technology in three-dimensional integration: An extensive review. J. Electron. Packag. 2018, 140, 010801. [CrossRef]

8. Liu, C.M.; Lin, H.W.; Chu, Y.C.; Chen, C.; Lyu, D.R.; Chen, K.N.; Tu, K.N. Low-temperature direct copper-to-copper bonding enabled by creep on highly (111)-oriented Cu surfaces. Scr. Mater. 2014, 12, 65-68. [CrossRef]

9. Yang, W.; Shintani, H.; Akaike, M.; Suga, T. Low Temperature Cu-Cu Direct Bonding Using Formic Acid Vapor Pretreatment. In Proceedings of the IEEE 61st Electronic Components and Technology Conference, Lake Buena Vista, FL, USA, 31 May-3 June 2011.

10. Chen, K.N.; Chang, S.M.; Shen, L.C.; Reif, R. Investigations of strength of copper-bonded wafers with several quantitative and qualitative tests. J. Electron. Mater. 2006, 35, 1082-1086. [CrossRef]

11. Utsumi, J.; Ichiyanagi, Y. Cu-Cu Direct Bonding Achieved by Surface Method at Room Temperature. In Proceedings of the Irago Conference, Tahara, Japan, 24-25 October 2013.

12. Tanaka, K.; Wang, W.S.; Baum, M.; Froemel, J.; Hirano, H.; Tanaka, S.; Wiemer, M.; Otto, T. Investigation of surface pre-treatment methods for wafer-level Cu-Cu thermo-compression bonding. Micromachines 2016, 7, 234. [CrossRef] [PubMed]

13. Koteswararao, B.; Suresh, Y.; Ravi, D. Analysis of quality in solid state welding (copper-copper) by using NDT and DT by altering physical properties at constant time. Mater. Today Proc. 2017, 4, 7351-7356.

14. Kumar, A.S.; Mohan, T.; Kumar, S.S.; Ravisankar, B. Destructive and Non-Destructive Evaluation of $\mathrm{Cu} / \mathrm{Cu}$ Diffusion Bonding with Interlayer Aluminum. IOP Conf. Ser. Mater. Sci. Eng. 2018, 330, 012045. [CrossRef]

15. Agapiou, J.S.; Perry, T.A. Resistance mash welding for joining of copper conductors for electric motors. J. Manuf. Processes 2013, 1, 549-557. [CrossRef]

16. Serge, M. RFQ vacuum brazing at CERN. In Proceedings of the EPAC08 Conference, Genoa, Italy, 23-27 June 2008. 
17. Singh, R.; Pant, K.K.; Lal, S.; Yadav, D.P.; Garg, S.R.; Raghuvanshi, V.K.; Mundra, G. Vacuum brazing of accelerator components. IOP J. Phys. Conf. Ser. 2012, 390, 012025. [CrossRef]

18. Zotti, L.A.; Teobaldi, G.; Palotás, K.; Ji, W.; Gao, H.J.; Hofer, W.A. Adsorption of benzene, fluorobenzene and meta-di-fluorobenzene on $\mathrm{Cu}(110)$ : A computational study. J. Comput. Chem. 2008, 29, 1589-1595. [CrossRef] [PubMed]

19. Copper. Available online: https://www.kupferinstitut.de/en/materials/material-properties/copper.html (accessed on 11 August 2019).

(C) 2019 by the authors. Licensee MDPI, Basel, Switzerland. This article is an open access article distributed under the terms and conditions of the Creative Commons Attribution (CC BY) license (http://creativecommons.org/licenses/by/4.0/). 